Neurodegener Dis 2017;17:110-116

DOI: 10.1159/000453359
Received: June 24, 2016

Accepted after revision: November 10, 2016

Published online: January 26, 2017

\title{
Environmental and Occupational Exposures and Amyotrophic Lateral Sclerosis in New England
}

\author{
Angeline S. Andrew ${ }^{a, b}$ Tracie A. Caller ${ }^{c}$ Rup Tandan ${ }^{d}$ Eric J. Duell ${ }^{f}$ \\ Patricia L. Henegan $^{\mathrm{b}}$ Nicholas C. Field ${ }^{\mathrm{b}}$ Walter G. Bradley \\ Elijah W. Stommel ${ }^{b}$
}

Departments of a Epidemiology and ${ }^{b}$ Neurology, Geisel School of Medicine at Dartmouth, Hanover, NH, 'Medical Specialty Clinic, Cheyenne Regional Medical Center, Cheyenne, WY, ${ }^{\mathrm{d}}$ Department of Neurological

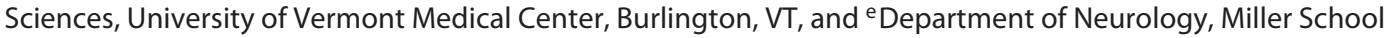
of Medicine, University of Miami, Miami, FL, USA; ${ }^{f}$ Cancer Epidemiology Research Program, Catalan Institute of Oncology (ICO-IDIBELL), Barcelona, Spain

\section{Keywords \\ Environmental exposure $\cdot$ Occupation · Toxicant $\cdot$ Water}

\section{Abstract}

Background: Recent data provide support for the concept that potentially modifiable exposures are responsible for sporadic amyotrophic lateral sclerosis (ALS). Objective: To evaluate environmental and occupational exposures as risk factors for sporadic ALS. Methods: We performed a casecontrol study of ALS among residents of New England, USA. The analysis compared questionnaire responses from 295 patients with a confirmed ALS diagnosis to those of 225 controls without neurodegenerative illness. Results: Self-reported job- or hobby-related exposure to one or more chemicals, such as pesticides, solvents, or heavy metals, increased the risk of ALS (adjusted OR 2.51; 95\% Cl 1.64-3.89). Industries with a higher toxicant exposure potential (construction, manufacturing, mechanical, military, or painting) were associated with an elevated occupational risk (adjusted OR 3.95; $95 \% \mathrm{Cl}$ 2.04-8.30). We also identified increases in the risk of ALS associated with frequent participation in water sports, particularly waterskiing (adjusted OR 3.89; 95\% Cl 1.97-8.44). Occupation and waterskiing both retained independent statistical significance in a composite model containing age, gender, and smoking status. Conclusions: Our study contributes to a growing body of literature implicating occupational- and hobby-related toxicant exposures in ALS etiology. These epidemiologic study results also provide motivation for future evaluation of water-body-related risk factors.

(c) 2017 S. Karger AG, Basel

\section{Introduction}

Amyotrophic lateral sclerosis (ALS) is a progressive, fatal neurodegenerative condition for which no cures exists and treatments are limited. In industrialized nations within Europe and North America, the incidence of ALS is approximately $1.5-2.5$ per 100,000 individuals, and it is higher in men than in women [1]. Despite the growing knowledge about the genetics of ALS, the majority of cases occur sporadically, without a clear family history. Current theories postulate that, similarly to cancer, ALS is a
(C) 2017 S. Karger AG, Basel

E-Mail karger@karger.com

www.karger.com/ndd
Angeline S. Andrew

Geisel School of Medicine at Dartmouth

Hinman 7936

Hanover, NH 03755 (USA)

E-Mail Angeline.Andrew@ dartmouth.edu 
multistep process and the disease develops when genetic susceptibilities and exposures to various risk factors occur together [2].

Many environmental and occupational risk factors have been evaluated, including certain occupations $[3,4]$, military service $[5,6]$, tobacco use $[7,8]$, electric shock [9], and head injury [10], as well as exposure to toxicants including organic solvents $[7,11]$, heavy metals such as lead [12] and mercury [13], pesticides [12, 14], and the cyanobacteria-derived neurotoxin $\beta-\mathrm{N}$-methylamino-Lalanine (BMAA) [15].

A recent umbrella review of existing meta-analyses and systematic reviews of nongenetic factors in the epidemiologic literature identified the toxic metal lead as the single risk factor that "presented convincing evidence for association with ALS" $\left(n=1,228\right.$ cases, $\left.p=2.13 \times 10^{-6}\right)$ [12]. Among the additional factors studied by meta-analysis, farming exposure, other heavy metals, and head injury were supported by "suggestive evidence", while electromagnetic fields and pesticides had "weak evidence", and smoking was not significantly associated [12]. These summarized data provide support for the concept that potentially modifiable exposures are responsible for sporadic ALS. Our objective was to evaluate the association between environmental/occupational exposures and ALS using a unique New England-based case-control study.

\section{Methods}

Participants were enrolled through the Department of Neurology at the Dartmouth-Hitchcock Medical Center (Lebanon, NH, USA) and the Department of Neurological Sciences at the University of Vermont Medical Center (Burlington, VT, USA). The eligible ALS patients were newly diagnosed cases with either probable or definite ALS according to Awaji-modified El Escorial criteria [16]. Eligible diagnoses included primary muscular atrophy but not primary lateral sclerosis. To decrease the influence of recall bias, we selected a control group consisting of neurology clinic patients with other idiopathic diseases that would prompt them to undertake a similar search for factors in their prior life that might have caused their disease. Diagnoses included multiple sclerosis, brain and spinal cord tumors, adult-onset epilepsy, and nonfamilial neuromuscular diseases, such as idiopathic peripheral neuropathies. Patients with neurodegenerative diseases, such as Alzheimer and Parkinson disease, were excluded from participation as controls. Participants were approached by study staff in the clinic, and they were required to be at least 21 years of old and residents of New England or the bordering New York region at the time of enrollment (ALS cases from June 2009 to December 2015 and controls from August 2010 to December 2015). Among the potential participants approached about this study, the questionnaire completion rate was $90 \%$ for ALS cases and $52 \%$ for controls. Reasons for nonparticipation among cases were effort required $(33 \%)$ and
Table 1. Population characteristics by ALS status

\begin{tabular}{lccl}
\hline Characteristic & $\begin{array}{c}\text { Controls } \\
(n=224)\end{array}$ & $\begin{array}{c}\text { Cases } \\
(n=295)\end{array}$ & $p$ value \\
\hline Gender & & & \\
$\quad$ Female & $106(47)$ & $105(36)$ & \\
$\quad$ Male & $118(53)$ & $190(64)$ & $0.010^{\mathrm{a}}$ \\
Median age, years & 61 & 62 & 0.54 \\
Family history of ALS & & & \\
$\quad$ No & $198(96)$ & $269(91)$ & \\
$\quad$ Yes & $9(4)$ & $25(9)$ & $0.07^{\mathrm{a}, \mathrm{b}}$ \\
Smoking status & $110(52)$ & $131(46)$ & \\
$\quad$ Never & $91(43)$ & $131(46)$ & $0.50^{\mathrm{a}, \mathrm{b}}$ \\
$\quad$ Former & $10(5)$ & $25(9)$ & $0.082^{\mathrm{a}, \mathrm{b}}$ \\
$\quad$ Current & $91(57)$ & $140(55)$ & \\
Pack-years & $41(26)$ & $59(23)$ & $0.83^{\mathrm{a}, \mathrm{b}}$ \\
$\quad$ None & $27(17)$ & $55(22)$ & $0.38^{\mathrm{a}, \mathrm{b}}$ \\
$\quad \begin{array}{l}\text { 1-20 } \\
\text { 20+ }\end{array}$ & & & \\
Concussion & $140(68)$ & $198(72)$ & \\
$\quad$ No & $67(32)$ & $78(28)$ & $0.22^{\mathrm{a}, \mathrm{b}}$ \\
$\quad$ Yes & $189(94)$ & $258(93)$ & \\
Electric shock & $12(6)$ & $19(7)$ & $0.61^{\mathrm{a}, \mathrm{b}}$ \\
$\quad$ No & & & \\
Yes & & & \\
\hline
\end{tabular}

Values are numbers (\%) unless otherwise stated. Missing data are as follows: age, $n=148$ ( $n=95$ controls, $n=45$ cases); family history, $n=18$; smoking, $n=21$; pack-years, $n=106$; concussion, $n=36$; and electric shock, $n=41$. ALS, amyotrophic lateral sclerosis. ${ }^{\mathrm{a}}$ Adjusted for age. ${ }^{\mathrm{b}}$ Adjusted for gender.

reluctance to share personal information (67\%), while controls cited time involved (33\%), social perception of sickness (32\%), reluctance to share personal information (18\%), and lack of a monetary benefit (17\%). For the current analysis, we had eligible participant questionnaire data on 295 ALS cases and 224 controls. All study procedures were approved by the Committee for Protection of $\mathrm{Hu}$ man Subjects at Dartmouth College and the Committee on $\mathrm{Hu}$ man Research in the Medical Sciences of the University of Vermont.

We evaluated environmental risk factors using a questionnaire based on the ALS Consortium of Epidemiologic Studies (ACES) modules. The questions analyzed included: family history of ALS, smoking status, concussion history, and occupational titles. "Did your job(s) or hobbies involve exposure to potentially harmful chemicals?" was used to ascertain exposure to toxic metals or pesticides. We also collected data on water body proximity and use. We asked, "Have you ever lived in a home located on or near (within a 2-mile distance) a lake, a river, a pond, an estuary, an ocean, or a body of water?" and "Have there ever been blue-green algae 'blooms' or green surface scum on the water body's surface?" Patients were asked to report if they participated in the following activities at least twice a month for a year or longer: swimming in lakes or rivers; boating, sailing, or kayaking; waterskiing, or windsurfing. Analyses are presented in relation to ALS risk in Tables 1-5. 
Table 2. Toxicant exposures and sources related to ALS status

\begin{tabular}{|c|c|c|c|c|}
\hline Toxicant & Controls & Cases & Overall $^{\mathrm{a}, \mathrm{b}}$ & Male $^{a}$ \\
\hline \multicolumn{5}{|c|}{ Use of chemicals (job or hobby) } \\
\hline No & $153(78)$ & $155(58)$ & Reference & Reference \\
\hline Yes & $44(22)$ & $113(42)$ & $2.51(1.64-3.89)$ & $1.88(1.12-3.19)$ \\
\hline \multicolumn{5}{|l|}{ Solvents } \\
\hline No & $169(87)$ & $198(75)$ & Reference & Reference \\
\hline Yes & $26(13)$ & $64(25)$ & $2.03(1.23-3.44)$ & $1.51(0.84-2.79)$ \\
\hline \multicolumn{5}{|l|}{ Lead } \\
\hline No & $184(95)$ & $229(87)$ & Reference & Reference \\
\hline Yes & $9(5)$ & $33(13)$ & $2.74(1.31-6.32)$ & $2.58(1.13-6.71)$ \\
\hline \multicolumn{5}{|l|}{ Mercury } \\
\hline No & $188(96)$ & $250(95)$ & Reference & Reference \\
\hline Yes & $7(4)$ & $13(5)$ & $1.35(0.53-3.77)$ & $1.5(0.48-5.62)$ \\
\hline \multicolumn{5}{|c|}{ Cooling/cutting lubricants } \\
\hline No & $188(96)$ & $254(97)$ & Reference & Reference \\
\hline Yes & $7(4)$ & $8(3)$ & $0.76(0.26-2.27)$ & $0.57(0.19-1.75)$ \\
\hline \multicolumn{5}{|l|}{ Pesticides } \\
\hline No & $187(96)$ & $228(87)$ & Reference & Reference \\
\hline Yes & $8(4)$ & $34(13)$ & $3.44(1.6-8.29)$ & $3.28(1.36-9.19)$ \\
\hline
\end{tabular}

Coding of occupational titles was performed manually using standardized occupation classification codes to assign job titles to an industry. We assessed the ALS risk associated with occupations that are likely to involve industrial chemical exposure, specifically participants with job titles involved in construction, manufacturing, mechanics, military, or painting (online suppl. Table S2; see www.karger.com/doi/10.1159/453359 for all online suppl. material). The title of the primary occupation was available for the majority $(86 \%)$ of the participants. The complete list of occupations held for $>6$ months was available in a subset $(26 \%)$ of participants. Coded occupational titles for ALS patients were analyzed in relation to the clinic-based control group (Table 4). For comparison purposes, the code for the primary occupation of the ALS patients was also analyzed in relation to the primary occupation of a different control group from a population-based study [17]. The population-control participants were shared from a prior study, which identified residents of New Hampshire or Vermont using a commercial database from Experian for the period of 2005-2006 [17]. The analysis was restricted to males $(n=94)$. Since the populationcontrol was aged 30-74 years, we restricted this supplementary analysis to the 169 male ALS patients within this age range (online suppl. Table S1). This analysis allowed us to see whether the results were consistent using a population-based control group with the results obtained using the clinic-based control group.

The risk of ALS associated with each specific exposure or lifestyle factor recorded in the questionnaire was modeled using casecontrol status as the outcome in a logistic regression analysis with adjustment for age and gender. Composite models were constructed to evaluate the independence of effects combining factors in a multivariate model. Logistic regression analyses were performed using R: a Language and Environment for Statistical Computing, version 3.2.3 (R Foundation for Statistical Computing, Vienna, Austria).

\section{Results}

Characteristics of the study population show that a higher proportion (64\%) of ALS patients were male, compared to $53 \%$ of the controls (Table 1). Controls and cases were similar in age (median ages 61 and 62). A family history of ALS in a blood relative was more common in ALS patients $(9 \%)$ than in controls (4\%). ALS patients were slightly more likely to have smoked within the year of enrollment than controls ( $9 \%$ of ALS patients vs. $5 \%$ of controls, $p=0.082$; Table 1 ).

The questionnaire requested information on job- or hobby-related use of the following chemicals: lead, mercury, solvents, cooling/cutting/lubricating oils, and pesticides. Self-reported exposure to chemicals was significantly associated with ALS risk (OR 2.51; 95\% CI 1.64-3.89, $p=0.00003$; Table 2). The specific chemical exposures most strongly associated with this increased ALS risk in models adjusted for age and gender were solvents $(p=0.0069)$, lead $(p=0.011)$, and pesticides $(p=0.028)$ (Table 2$)$. 
Table 3. Occupations related to ALS status

\begin{tabular}{|c|c|c|c|c|}
\hline & Controls & Cases & Overall $^{\mathrm{a}, \mathrm{b}}$ & Male $^{\mathrm{a}}$ \\
\hline \multicolumn{5}{|l|}{ Military service } \\
\hline Never & $166(80)$ & $205(72)$ & Reference & Reference \\
\hline Ever & $42(20)$ & $79(28)$ & $1.09(0.67-1.78)$ & $1.49(0.88-2.54)$ \\
\hline \multicolumn{5}{|l|}{ Deployed } \\
\hline Never & $179(87)$ & $237(86)$ & Reference & Reference \\
\hline Ever & $27(13)$ & $39(14)$ & $0.73(0.41-1.31)$ & $0.96(0.53-1.76)$ \\
\hline \multicolumn{5}{|c|}{ Primary occupation involving industrial chemicals } \\
\hline No & $169(94)$ & $210(79)$ & Reference & Reference \\
\hline Yes & $11(6)$ & $55(21)$ & $3.95(2.04-8.3)$ & $8.74(3.37-29.9)$ \\
\hline Construction & $2(1)$ & $17(6)$ & & \\
\hline Manufacturing & $5(3)$ & $25(9)$ & & \\
\hline Mechanics & $0(0)$ & $6(2)$ & & \\
\hline Military & $0(0)$ & $6(2)$ & & \\
\hline Painting & $4(2)$ & $1(0)$ & & \\
\hline \multicolumn{5}{|c|}{ Ever held an occupation for $>6$ months involving industrial chemicals } \\
\hline No & $69(76)$ & $22(51)$ & Reference & Reference \\
\hline Yes & $22(24)$ & $21(49)$ & $4.24(1.59-12.45)$ & $4.86(1.65-16.21)$ \\
\hline
\end{tabular}

Table 4. Water body proximity and use in relation to ALS status

\begin{tabular}{|c|c|c|c|}
\hline Exposure & Controls & Cases & $\mathrm{OR}^{\mathrm{a}}(95 \% \mathrm{CI})$ \\
\hline \multicolumn{4}{|c|}{ Resides full-time within 2 miles of a water body } \\
\hline No & $65(33)$ & $64(23)$ & Reference \\
\hline Yes & $132(67)$ & $214(77)$ & $1.59(1.05-2.42)$ \\
\hline \multicolumn{4}{|c|}{ If yes, algae have bloomed in that water body } \\
\hline No & $90(73)$ & $143(74)$ & Reference \\
\hline Yes & $33(27)$ & $50(26)$ & $1.06(0.62-1.84)$ \\
\hline \multicolumn{4}{|c|}{ Has gone waterskiing $\geq 2 \times$ per month for 1 year or more } \\
\hline No & $178(95)$ & $207(81)$ & Reference \\
\hline Yes & $10(5)$ & 47 (19) & $3.89(1.97-8.44)$ \\
\hline \multicolumn{4}{|c|}{ Has gone boating, sailing, or kayaking $\geq 2 \times$ per month for 1 year or more } \\
\hline No & $126(68)$ & $153(58)$ & Reference \\
\hline Yes & $59(32)$ & $111(42)$ & $1.51(1.01-2.28)$ \\
\hline \multicolumn{4}{|c|}{ Has gone windsurfing $\geq 2 \times$ per month for 1 year or more } \\
\hline No & $177(94)$ & $240(96)$ & Reference \\
\hline Yes & $12(6)$ & $11(4)$ & $0.6(0.25-1.42)$ \\
\hline \multicolumn{4}{|c|}{ Has gone swimming $\geq 2 \times$ per month for 1 year or more } \\
\hline No & $106(55)$ & $122(46)$ & Reference \\
\hline Yes & $87(45)$ & $143(54)$ & $1.43(0.97-2.1)$ \\
\hline
\end{tabular}

Values are numbers (\%) unless otherwise stated. Missing data are as follows: residing, $n=44$; blooming, $n=$ 30; waterskiing, $n=77$; boating, $n=70$; windsurfing, $n=79$; and swimming, $n=61$. ALS, amyotrophic lateral sclerosis. ${ }^{\text {a }}$ Adjusted for age and gender. 
Table 5. Composite models of ALS risk factors

\begin{tabular}{|c|c|c|c|c|}
\hline & Controls & Cases & Overall $^{\mathrm{a}, \mathrm{b}}$ & Male $^{\mathrm{a}}$ \\
\hline \multicolumn{5}{|c|}{ Smoking status } \\
\hline Never & $110(52)$ & $131(46)$ & Reference & Reference \\
\hline Former & $91(43)$ & $131(46)$ & $1.12(0.72-1.75)$ & $1.3(0.7-2.43)$ \\
\hline Current & $10(5)$ & $25(9)$ & $2.48(0.96-7.27)$ & $2.72(0.83-10.82)$ \\
\hline \multicolumn{5}{|c|}{ Primary occupation involves industrial chemicals } \\
\hline No & $169(94)$ & $210(79)$ & Reference & Reference \\
\hline Yes & $11(6)$ & $55(21)$ & $4.1(1.91-9.87)$ & $2.45(1.21-5.2)$ \\
\hline \multicolumn{5}{|c|}{ Waterskiing $\geq 2 \times$ per month for 1 year or more } \\
\hline No & $178(95)$ & $207(81)$ & Reference & Reference \\
\hline Yes & $10(5)$ & 47 (19) & $3.71(1.8-8.47)$ & $2.91(1.18-8.3)$ \\
\hline
\end{tabular}

Values are numbers $(\%)$ or OR $(95 \% \mathrm{CI})$. Missing data are as follows: smoking status, $n=21$; primary occupation, $n=74$; and water-skiing, $n=77$. ${ }^{\mathrm{a}}$ OR adjusted for age. ${ }^{\mathrm{b}}$ OR adjusted for gender.

Compared to other occupations, an increased risk of ALS was associated with both having a primary occupation that likely involves industrial chemicals (coded as construction, manufacturing, mechanics, military, or painting; OR 3.95; 95\% CI 2.04-8.30) and having a history of ever holding such an occupation for 6 months or longer (OR 4.24; 95\% CI 1.59-12.45), adjusted for age and gender (Table 3). A similar risk elevation was observed in an analysis of primary occupations restricted to males (Table 3).

Patients reported ever having lived full-time within 2 miles of a water body more frequently than did controls (77\% of ALS patients vs. $67 \%$ of controls; OR 1.59; $95 \%$ CI 1.05-2.42; Table 4). A large proportion of participants reported boating, sailing, or kayaking ( $42 \%$ of ALS patients and $32 \%$ of controls; OR 1.51; 95\% CI 1.01-1.42). Frequent participation in waterskiing was associated with a 3-fold higher risk (OR 3.89; 95\% CI 1.97-8.44).

In a composite model including multiple risk factors, with adjustment for age, gender, and smoking status, we observed statistically significant increased ALS risks independently associated with frequent waterskiing $(p=$ 0.00066 ) and a primary occupation using industrial chemicals ( $p=0.00081$; Table 5 ). These $p$ values remained statistically significant with consideration for multiple comparisons $(p<0.006)$.

Validation analysis of coded primary occupational titles for male ALS patients in relation to males from a population-based control group showed a consistent, positive association with exposure to industrial chemicals (ageadjusted OR 2.97; 95\% CI 1.47-6.39; online suppl. Table S1).

\section{Discussion}

ALS is a multistep progressive lethal disease characterized by muscle weakness due to a loss of motor neurons [2]. Our epidemiologic study of ALS risk factors in Northern New England strongly supports a major role for environmental chemicals and occupational exposures in the disease etiology. This study also introduces new human evidence of a possible water-body-related exposure factor.

Consistent with the 2016 umbrella review of metaanalyses that established convincing evidence of an association between ALS and lead exposure, we found that the risk of ALS was increased 2.7-fold among our patients reporting jobs or hobbies that cause lead exposure [12]. Blood levels of lead have been reported to be elevated in ALS patients $[18,19]$.

The umbrella review also found a statistically significant 1.44-fold increased risk of pesticide exposure in $>1,000$ cases [12]. We found a 3.4-fold risk associated with self-reported pesticide exposure, consistent with several other population studies [4, 20-22]. Excess ALS mortality was reported among workers exposed to a component of the herbicide Agent Orange 2,4-diphenoxyacetic acid (RR 3.45; 95\% CI 1.10-11.11) compared to others who were not so exposed but worked for the same employer [23]. A recent paper related blood levels of several organochlorine pesticides [pentachlorobenzene $(p=$ $0.04)$ and cis-chlordane $(p=0.005)]$ to increased odds of ALS [22].

In addition to lead and pesticides, the 1.8 -fold risk we observed with exposure to solvents is consistent with the increased ALS risk identified from exposure to cleaning 
solvents or degreasers in Washington state both via selfreport (OR 1.8; 95\% CI 1.2-2.8) and inferred from exposure based on occupation (OR 1.9; 95\% CI 1.1-3.3) [24]. A matched case-control study $(n=51)$ also identified an elevated ALS risk associated with residential exposure to aromatic solvents (OR 5.03; 95\% CI 1.29-19.53) [11].

The results of our occupational analysis are consistent with some prior studies but not others. Another casecontrol study conducted in New England from 1993 to 1996 found a similar increased risk of ALS for workers ever employed as construction workers (OR 2.9; 95\% CI 1.2-7.2) or production workers (OR 2.2; 95\% CI 1.1-4.4), particularly precision metal workers (OR 3.5; 95\% CI 1.210.5) [25]. Important classes of chemicals inferred from the occupational data in this study showing an elevated ALS risk included aliphatic chlorinated hydrocarbons, ethylene/propylene glycols, glycol ethers, heptane, and hexane [25]. On the other hand, a US nationwide prospective cohort of 1 million participants followed from 1982 to 2002 did not show statistically significant associations between the longest held occupation and ALS mortality [26].

Our composite model indicated a 3-fold association between waterskiing and ALS risk that is independent of age, gender, smoking, exposure to chemicals, and occupation. Exposure to cyanobacteria and the cyanotoxin BMAA is one possible explanation for the association of an increased risk of ALS and exposure to water bodies. Exposure routes for cyanotoxins that have been proposed include inhalation of aerosolized particles (which could occur during activities such as waterskiing) [27], ingestion, and direct contact through water sports [28]. A recent animal model study demonstrated that vervet monkeys chronically fed BMAA developed tauopathies similar to those seen in neurodegenerative diseases like Alzheimer's disease and ALS [29]. It is unclear to what degree the water body associations we observed might have been due to BMAA versus other causes. Our results motivate further investigation of water-body-related environmental risk factors.

Limitations of our study include relatively small sample sizes that impair statistical power within certain subgroups. Detailed information on the dates of participation or exposure were not collected, and thus we could not calculate latency. Our primary analyses of risk factors for ALS were based on comparisons of ALS patients with controls recruited among patients with idiopathic neurological diseases that, as in ALS, often cause patients to search their memories for possible lifetime exposures that might have caused their disease. Although some of the diagnoses of the clinic-based controls could have risk factors in common with ALS, such relationships would be expected to bias the results towards the null. We hoped thereby to correct for differential recall of events (recall bias). We found that exposure to only certain environmental factors and not all was statistically significantly associated with ALS, which adds weight to the conclusion that these associations are real and not due to recall bias. For example, exposure to lead, but not exposure to mercury, was associated with an increased ALS risk. A potential drawback of the use of clinic-based controls is that recall bias would increase the frequency of reported exposures in both groups, thereby reducing the likelihood of detecting important environmental exposure risks. However, when we compared the responses of the clinic control patients to those of our population-based controls, we found that clinic controls reported less frequently occupations with a likely exposure to chemicals than the population-based controls ( 7 vs. $14 \%$ ), though the difference was not statistically significant. Therefore, we believe that recall bias did not significantly influence the results of our study and that the observed positive associations for ALS risk factors are likely robust. In addition, the results of the Behavioral Risk Factor Surveillance Survey of the Centers for Disease Control (CDC) show that $47 \%$ of 55 - to 64 -year-olds in New Hampshire are never-smokers, indicating that the smoking history of our clinic-based controls our is similar to that of the general population in the region [30].

Our results provide evidence of environmental and occupational exposures that likely play a role in the etiology of sporadic ALS. Future investigations using biosamplebased exposure assessment will be useful for elucidating the more detailed dose and specific chemical class relationships. Our findings also suggest that further investigation of water-body-related factors in additional populations is warranted. ALS may have a multistage etiology involving "hits" from several different genetic and environmental factors [31]. Identifying the preventable exposures that increase the risk of ALS is a critical step in reducing the incidence of this devastating disease.

\section{Acknowledgments}

We would like to thank the study participants and our sources of funding: ALS Association grants SC5181 and 15-IIP-213, CDC/ Agency for Toxic Substances and Disease Registry (ATSDR) contract 200-2014-59046, and the Dartmouth Clinical and Translational Science Institute, under award number KL2TR001088 from the National Center for Advancing Translational Sciences (NCATS) of the National Institutes of Health (NIH). 


\section{Disclosure Statement}

The authors declare that they have no actual or potential com-

peting financial interests.

\section{References}

1 Chio A, Logroscino G, Traynor BJ, Collins J, Simeone JC, Goldstein LA, White LA: Global epidemiology of amyotrophic lateral sclerosis: a systematic review of the published literature. Neuroepidemiology 2013;41:118130.

2 Al-Chalabi A, Calvo A, Chio A, Colville S, Ellis CM, Hardiman O, Heverin M, Howard RS, Huisman MH, Keren N, Leigh PN, Mazzini L, Mora G, Orrell RW, Rooney J, Scott KM, Scotton WJ, Seelen M, Shaw CE, Sidle KS, Swingler R, Tsuda M, Veldink JH, Visser AE, van den Berg LH, Pearce N: Analysis of amyotrophic lateral sclerosis as a multistep process: a population-based modelling study. Lancet Neurol 2014;13:1108-1113.

3 Sutedja NA, Fischer K, Veldink JH, Van Der Heijden GJ, Kromhout H, Heederik D, Huisman MH, Wokke JJ, Van Den Berg LH: What we truly know about occupation as a risk factor for ALS: a critical and systematic review. Amyotroph Lateral Scler 2009;10:295-301.

4 Malek AM, Barchowsky A, Bowser R, Heiman-Patterson T, Lacomis D, Rana S, Youk A, Stickler D, Lackland DT, Talbott EO: Environmental and occupational risk factors for amyotrophic lateral sclerosis: a case-control study. Neurodegener Dis 2014;14:31-38.

5 Beard JD, Kamel F: Military service, deployments, and exposures in relation to amyotrophic lateral sclerosis etiology and survival. Epidemiol Rev 2015;37:55-70.

6 Weisskopf MG, Cudkowicz ME, Johnson N: Military service and amyotrophic lateral sclerosis in a population-based cohort. Epidemiology 2015;26:831-838.

7 Fang F, Quinlan P, Ye W, Barber MK, Umbach DM, Sandler DP, Kamel F: Workplace exposures and the risk of amyotrophic lateral sclerosis. Environ Health Perspect 2009;117: 1387-1392.

8 Schmidt S, Kwee LC, Allen KD, Oddone EZ: Association of ALS with head injury, cigarette smoking and APOE genotypes. J Neurol Sci 2010;291:22-29.

9 Abhinav K, Al-Chalabi A, Hortobagyi T, Leigh PN: Electrical injury and amyotrophic lateral sclerosis: a systematic review of the literature. J Neurol Neurosurg Psychiatry 2007; 78:450-453.

10 Pupillo E, Messina P, Logroscino G, Zoccolella S, Chio A, Calvo A, Corbo M, Lunetta C, Micheli A, Millul A, Vitelli E, Beghi E; EURALS Consortium: Trauma and amyotrophic lateral sclerosis: a case-control study from a population-based registry. Eur J Neurol 2012;19:1509-1517.
11 Malek AM, Barchowsky A, Bowser R, Heiman-Patterson T, Lacomis D, Rana S, Ada Y Talbott EO: Exposure to hazardous air pollutants and the risk of amyotrophic lateral sclerosis. Environ Pollut 2015;197:181-186.

12 Belbasis L, Bellou V, Evangelou E: Environmental risk factors and amyotrophic lateral sclerosis: an umbrella review and critical assessment of current evidence from systematic reviews and meta-analyses of observational studies. Neuroepidemiology 2016;46:96-105.

13 Johnson FO, Atchison WD: The role of environmental mercury, lead and pesticide exposure in development of amyotrophic lateral sclerosis. Neurotoxicology 2009;30:761-765.

14 McGuire V, Longstreth WT Jr, Nelson LM, Koepsell TD, Checkoway H, Morgan MS, van Belle G: Occupational exposures and amyotrophic lateral sclerosis: a population-based case-control study. Am J Epidemiol 1997;145: 1076-1088.

15 Banack SA, Caller TA, Stommel EW: The cyanobacteria derived toxin beta-N-methylamino-L-alanine and amyotrophic lateral sclerosis. Toxins (Basel) 2010;2:2837-2850.

16 Costa J, Swash M, de Carvalho M: Awaji criteria for the diagnosis of amyotrophic lateral sclerosis: a systematic review. Arch Neurol 2012;69:1410-1416.

17 Heck JE, Andrew AS, Onega T, Rigas JR, Jackson BP, Karagas MR, Duell EJ: Lung cancer in a US population with low to moderate arsenic exposure. Environ Health Perspect 2009;117: 1718-1723.

18 Kamel F, Umbach DM, Munsat TL, Shefner JM, Hu H, Sandler DP: Lead exposure and amyotrophic lateral sclerosis. Epidemiology 2002;13:311-319.

19 Fang F, Kwee LC, Allen KD, Umbach DM, Ye W, Watson M, Keller J, Oddone EZ, Sandler DP, Schmidt S, Kamel F: Association between blood lead and the risk of amyotrophic lateral sclerosis. Am J Epidemiol 2010;171:11261133.

20 Gunnarsson LG, Lindberg G, Soderfeldt B, Axelson O: Amyotrophic lateral sclerosis in Sweden in relation to occupation. Acta Neurol Scand 1991;83:394-398.

21 Bonvicini F, Marcello N, Mandrioli J, Pietrini V, Vinceti M: Exposure to pesticides and risk of amyotrophic lateral sclerosis: a populationbased case-control study. Ann Ist Super Sanita 2010;46:284-287.
22 Su FC, Goutman SA, Chernyak S, Mukherjee B, Callaghan BC, Batterman S, Feldman EL: Association of environmental toxins with amyotrophic lateral sclerosis. JAMA Neurol 2016;73:803-811.

23 Burns CJ, Beard KK, Cartmill JB: Mortality in chemical workers potentially exposed to 2,4-dichlorophenoxyacetic acid (2,4-D) 1945-94: an update. Occup Environ Med 2001;58:24-30.

24 McGuire V, Longstreth WT Jr, Nelson LM, Koepsell TD, Checkoway H, Morgan MS, van Belle G: Occupational exposures and amyotrophic lateral sclerosis: a population-based case-control study. Am J Epidemiol 1997;145: 1076-1088.

25 Fang F, Quinlan P, Ye W, Barber MK, Umbach DM, Sandler DP, Kamel F: Workplace exposures and the risk of amyotrophic lateral sclerosis. Environ Health Perspect 2009;117: 1387-1392.

26 Weisskopf MG, McCullough ML, Morozova N, Calle EE, Thun MJ, Ascherio A: Prospective study of occupation and amyotrophic lateral sclerosis mortality. Am J Epidemiol 2005; 162:1146-1152.

27 Stommel EW, Field NC, Caller TA: Aerosolization of cyanobacteria as a risk factor for amyotrophic lateral sclerosis. Med Hypotheses 2013;80:142-145

28 Stewart I, Webb PM, Schluter PJ, Shaw GR: Recreational and occupational field exposure to freshwater cyanobacteria - a review of anecdotal and case reports, epidemiological studies and the challenges for epidemiologic assessment. Environ Health 2006;5:6.

29 Cox PA, Davis DA, Mash DC, Metcalf JS, Banack SA: Dietary exposure to an environmental toxin triggers neurofibrillary tangles and amyloid deposits in the brain. Proc Biol Sci 2016;283:20152397.

30 Centers for Disease Control and Prevention: BRFSS prevalence and trends data. http:// www.dev.cdc.gov/brfss/brfssprevalence/.

31 Al-Chalabi A, Calvo A, Chio A, Colville S, Ellis CM, Hardiman O, Heverin M, Howard RS, Huisman MH, Keren N, Leigh PN, Mazzini L, Mora G, Orrell RW, Rooney J, Scott KM, Scotton WJ, Seelen M, Shaw CE, Sidle KS, Swingler R, Tsuda M, Veldink JH, Visser AE, van den Berg LH, Pearce N: Analysis of amyotrophic lateral sclerosis as a multistep process: a population-based modelling study. Lancet Neurol 2014;13:1108-1113. 